\title{
Application of Course Ideological and Political Education into Traditional Chinese Medicine Courses in Western Medical Colleges
}

\author{
Shengjun Yin ${ }^{1}$, Yi Sun ${ }^{2}$, Gang Zhang ${ }^{1}$, Wei Liu ${ }^{1 *}$ \\ ${ }^{1}$ The Department of Traditional Chinese Medicine, The Second Hospital of Tianjin Medical University, Tianjin 300211, China \\ ${ }^{2}$ The Department of Nephrology, The Second Affiliated Hospital of Tianjin University of TCM, Tianjin 300250, China \\ Email: gaoyuanzhe971015@163.com
}

\begin{abstract}
Medicine is benevolence, and the ultimate goal of medicine is to pursue human health. Medical higher education should not only be responsible for the teaching of professional knowledge, but also pay more attention to ideological and moral education. Therefore, it is particularly important to practice course ideological and political education. Traditional Chinese medicine (TCM) is the excellent traditional culture of our country. Traditional Chinese medicine courses in Western medical colleges should not only teach the basic knowledge of traditional Chinese medicine, but also carry out course ideological and political education based on Chinese excellent traditional culture. This article summarizes teaching experience to discuss the content and form of course ideological and political education in TCM teaching. Through the combination of professional knowledge, cultural heritage and ideological and political education, it is possible to cultivate all-round medical talents with both political integrity and ability.
\end{abstract}

Keywords: traditional Chinese medicine courses, course ideological and political education, traditional culture

\section{Introduction}

President Xi Jinping pointed out at the 2016 National Conference on Ideological and Political Work in Colleges and Universities, "We must persist in taking strengthening moral education and cultivating people as the central link, carry out ideological and political work throughout the whole process of education and teaching, educate people in the whole process and in all directions, and strive to create a new situation in the development of China's higher education" ${ }^{[1]}$. With the development of society, all kinds of information are numerous and complicated, and college students in the active stage of thinking are more likely to be "fascinated and dazzled". The younger generation is the core component of human resources in the new century and the hope of the country. Therefore, it is of great significance to carry out ideological and moral education among students in colleges and universities. Only by strengthening the cultivation of their political ideology and moral quality can they establish their correct values, outlook on life, and world outlook, so that they can apply what they have learned and become the pillars of the motherland. President Xi Jinping pointed out, "All courses have the function of educating people, and ideological and political work cannot be regarded only as the job of the political theory course. All other courses must do their duties." Medicine is benevolence. Medicine takes people as the research object, and takes the pursuit of human health as the starting point and the ultimate goal. It is particularly important to develop course ideological and political education in medical colleges. Traditional Chinese medicine is a representative of the excellent traditional culture of our country and one of the symbols of the Chinese nation. Therefore, the ideological and political education of traditional Chinese medicine courses in Western medical colleges shoulder the important task of cultural inheritance. Based on the characteristics of traditional Chinese medicine courses, the author explores the ideological and political reform of the whole process and multiple styles in teaching, and integrates the excellent traditional Chinese culture, socialist core values, and life principles of being a man and doing things in the teaching of professional knowledge.

\section{The connotation of curriculum ideology}

"Course ideological and political education" is to run Marxist theory through the whole process of teaching and research; to dig deep into the ideological and political theory education resources of various courses; to construct the ideological and political education course system of "trinity" of ideological and theoretical courses, comprehensive literacy courses and professional education courses from a strategic perspective; to promote the education and teaching of all majors to be good at using Marxist positions, viewpoints and methods; to explore important ways for various courses and ideological and political theory courses to go in the same direction and form synergistic effect ${ }^{[2]}$.

Carrying out ideological and political education is not to set up another political course, but to enable students to expand their thinking, improve humanistic quality and establish good psychological quality while learning professional 
knowledge, so as to prepare for entering the society. The future competition is fierce, and the development of students' life requires good comprehensive qualities. Carrying out effective ideological and political education has positive significance for individuals and the country.

The connotation of course ideological and political education is not only ideological and political education, but also combining professional knowledge with family and country feelings, outlook on life, values, and world outlook, so that students can complete the promotion of moral sentiment and national responsibility and internalize the core values of socialism into the organic composition of their own spiritual system. When it comes to the TCM courses in Western medical colleges, the connotation of course ideological and political education is to enable students to accept TCM while learning the basic theories of TCM, broaden their thinking of clinical diagnosis and treatment, realize the profoundness of Chinese culture, and improve their recognition and persistence of traditional Chinese culture, strengthen national selfconfidence, and establish a correct outlook on life and values. This can not only give play to the educational function of traditional Chinese medicine courses, but also show the core position of ideological and political theory courses in the education of socialist core values, which is helpful to realize the goal of ideological and political education in all directions and to achieve the implicit education that nourishes all things quietly ${ }^{[2]}$.

\section{Features of traditional Chinese medicine courses}

Ideological and political education and medicine are both responsible for treating diseases and saving people. Medicine can relieve people's physical pain, while ideological and political education can solve people's ideological problems. Therefore, the medical courses contain ideological and political elements everywhere. The medical courses in the Western colleges include basic theories of traditional Chinese medicine and the basic knowledge of diagnostics of traditional Chinese medicine, traditional Chinese medicine, prescription, internal medicine of traditional Chinese medicine, acupuncture and moxibustion and so on. Because students have little knowledge about Chinese medicine, it is difficult for them to establish another medical thinking mode in a short time. For example, as the opening part, the basic theory of traditional Chinese medicine is the most difficult and necessary content for students in the course of traditional Chinese medicine because it is abstract and profound, the teaching form is simple, the available information-based teaching methods are few, and it is difficult to express them intuitively. They are prone to the phenomena of unclear knowledge points, weariness of learning and so on ${ }^{[3]}$. Although the internal medicine part of traditional Chinese medicine can be associated with and compared with the relevant contents of western medicine, due to different philosophical backgrounds, students are easy to adopt the learning and thinking way of "relying on Western medicine to study traditional Chinese medicine". Therefore, it is necessary to combine the characteristics of traditional Chinese medicine courses to carry out effective course ideological and political education. This puts forward higher requirements for the integration methods and angles of ideological and political content, teaching methods, teachers' professional theoretical accomplishment and ideological and political level. Traditional Chinese medicine is the essence of Chinese culture. In our teaching practice, we should connect various ideological and political elements with culture as the main line to build a multi-dimensional ideological and political aspect.

\section{Course ideological and political education is organically integrated into the traditional Chinese medicine courses in Western medical colleges}

\subsection{Ideological and political elements contained in TCM theory}

The brilliance of ideological and political elements is shining in many places in traditional Chinese medicine courses. Through careful excavation, the principles of traditional Chinese medicine and society contained in it can be taught in fun, and ideological and political education can be integrated into classroom teaching, so as to achieve a good effect of moisturizing all things in silence.

The introduction part discusses the forming background, historical context and basic characteristics of traditional Chinese medicine, advocating the students to inherit and carry forward the excellent traditional culture as their own duty. By introducing the family and national feelings and personality charm of famous doctors in past dynasties, cultivate students' sense of social responsibility of "worrying before the people fear something will happen, and being happy after the people are happy".

The theory of yin-yang and the five elements in the basic theory of traditional Chinese medicine is the key and difficult point. It links the relationship between yin and yang with the contradiction theory of dialectical materialism, and links the self-regulation mechanism of interpromotion and interrestraint of the five elements with the principles of being 
a man and doing things. This can not only help students understand the basic concepts of the theory of yin-yang and the five elements, but also inspire students to look at everything in nature with dialectical thinking, and to look at the principle of isomorphism between man and nature and the principle of acceptance with the same kind of thinking. It can also help students understand the great ecological medical thought of traditional Chinese medicine, which can also help students establish the awareness of protecting the environment, adapting to the society, and dealing with the pros and cons of life correctly.

The prevention and treatment part emphasizes the unity of nature and man, and prevention before illness. Suwen $\cdot$ The Great Theory of Regulating the Mind of the Four Qi records, "Therefore, sages do not wait for the disease to be treated, but prevent it before it attacks; they do not deal with the chaos after it has occurred, but take precautions before it occurs. That is the truth. If the disease is treated only when it has attacked, and the chaos is not dealt with until it has occurred, it is like digging a well when you are thirsty and casting weapons only when you have to fight. Isn't it too late? Lingshu $\cdot \mathrm{Ci}$ Jie Zhen Xie repeatedly emphasizes that man "corresponds to the heaven and the earth, corresponds to the four seasons". The explanation of classic famous sentences in ancient books allows students to understand that man and nature, man and society are a whole, and that human diseases are closely related to people and their natural and social environment. At the same time it inspires students to pay attention to the whole and the individual in their outlook on life, values, and the truth of life and doing things, and to set up the overall consciousness and the idea of overall adjustment.

In the part of diagnostics of traditional Chinese medicine, in addition to the explanation of professional knowledge, it is more about teaching students how to communicate with patients and be able to treat patients and their families with "benevolence". On the Absolute Sincerity of Great Physicians by Sun Simiao from the Tang dynasty should be learned. That the ancient doctors treated patients with "a heart of sympathy" and "the thought of the closest relatives" should be associated with that take the patient as the center, save the dead and heal the wounded, and implement revolutionary humanitarianism today. Let students understand that they should not only have superb medical skills, but also noble medical ethics, and should not be corrupted by money worship and hedonism to do things contrary to medical ethics.

In the part of traditional Chinese pharmacology and science of prescriptions, the inspirational deeds of Professor Tu Youyou and artemisinin can be interspersed. Promote the spirit of scientists to explore and innovate and introduce the positive energy of the times and society into the courses. Students are urged to learn the noble sentiment of scientists' dedication to science and their practical and realistic working attitude, and think about how to improve the scientific literacy and innovative consciousness of multidisciplinary integration as medical students, so as to make their own contributions to the development of medicine.

\subsection{Traditional Chinese medicine is the representative of Chinese excellent culture}

Cultural self-confidence is the full affirmation and active practice of the cultural values for a nation, a country and a political party, and the firm confidence in their cultural vitality. President Xi Jinping once pointed out, "Traditional Chinese medicine is the treasure of Chinese civilization, an important carrier of excellent traditional culture, and a key to Chinese civilization." The traditional Chinese medicine courses contain rich connotations of nature, humanities and social sciences. The world outlook, outlook on life, morality, and ethics of traditional culture and the outlook on nature, life, diseases, diagnosis and treatment and prevention in traditional Chinese medicine all embody the quintessence of Chinese culture ${ }^{[4]}$. Under the nourishment of traditional Chinese ethical culture, TCM culture incorporates many cultural highlights represented by Confucianism and Taoism, such as the Confucian theory that man is an integral part of nature, thought to put people first, and doctrine of the mean, as well as Taoistic "tao way follows nature", "theory of inaction" and "indifference to fame or gain, and nihility". In teaching, integrating the promotion of traditional Chinese medicine culture into teaching can enable students to enhance their national cultural self-confidence. The core values of traditional Chinese medicine culture defined in the Guidelines for the Construction of TCM Culture in TCM Hospitals promulgated by the State Administration of Traditional Chinese Medicine in July 2009, such as "put people first" "man is an integral part of nature" "medicine is benevolence" "harmony" and "virtue of great physicians", can be summarized in the words "benevolence, harmony, excellence, and sincerity". Combining the professional background of medical colleges and universities, we can cultivate students' humanitarianism spirit of reverence and respect for life and social responsibility of saving the world through "benevolence"; through the thought of "harmony" and the policy of attaching equal importance to traditional Chinese and Western medicine, we can cultivate students' broad mind in dealing with things.

4.2.1 If harmony is achieved, all things can grow and develop. If they are exactly the same, they will not be able to develop and continue.

The thought of "harmony" is respected by many thinkers in history, and it embodies the quintessence of excellent Chinese traditional culture. "Harmony" includes many aspects, such as man and nature, man and society, man and man, 
man's body and mind and so on. "Man is an integral part of nature" refers to the harmony and unity of man and nature, and the harmony of human behavior with nature; "harmony of body and mind" refers to the harmony between body and spirit, and the harmony between man's subjective desire and the objective development of things, so as to achieve the harmony and unity of man himself. The higher-level meaning of "harmony" is tolerance, emphasizing learning from each other's strengths to offset their weaknesses in mutual independence. "Harmonious but different" requires the recognition of differences, symbiosis and coexistence, and the realization of balance. "Seeking common ground while reserving differences" requires mutual respect, mutual learning, and drawing on the strong points of others to make up for one's own weak points. With the continuous changes of the current situation at home and abroad, the thoughts of college students are easily influenced by Western politics, economy and culture, and there will inevitably be some factors that are not harmonious with the socialist system. Therefore, integrating the thought of "harmony" into college students' ideological and political education is the need to improve college students' political literacy. College students in the new era should strengthen moral cultivation, pay attention to moral practice and consciously practice socialist core values from the connotation of Chinese excellent traditional culture and socialist core values. They should not only learn advanced science and technology, but also resist the erosion of wrong trends of thought and strengthen their ideological beliefs.

\subsubsection{Medicine is benevolence}

"Benevolence" is a concentrated expression of Confucian friendly thoughts, the quintessence of thoughts that have been precipitated by the Chinese nation over thousands of years, and the fine traditional virtue of the Chinese nation. The Analects and Mencius interpret "benevolence" as "loving others" and "heart of compassion" respectively. Han Yu believed that "universal love is benevolence" and $\mathrm{Zhu} \mathrm{Xi}$ called for "universal love". Benevolence is used not only to treat family members and relatives, but also to treat everyone. The Analects $\cdot$ Xue Er pointed out, "Young students are filial to their parents when they go home, and respect their elder brothers when they leave their homes; they are cautious, honest and trustworthy; they love the public and are close to virtuous people."

Mencius · King Lianghui pointed out, "When raising and honoring one's elders, one should not forget other elderly people who are not related to oneself. When raising and educating one's own children, one should not forget other children who are not related to oneself." In The Analects Confucius further discussed how to love others, how to deal with relationships with others, and how to establish harmonious interpersonal relationships. The Analects · Wei Ling Gong pointed out, "Don't impose on others what you don't want to accept." The Analects · Yong Ye pointed out that we should judge another person's feelings by our own, put ourselves in consideration of the interests and needs of others, and help others as much as possible.

TCM culture transforms the "benevolence" in Confucian culture into "medicine is benevolence". In thousands of years of medical inheritance and development, it advocated people-oriented thought and valuing people, and it regarded the value of human life as the supreme. Suwen - Bao Ming Quan Xing Theory pointed out that "people are the most precious". Sun Simiao of the Tang dynasty emphasized that "human life is very important, and it is more valuable than a lot of money". Li Shizhen of the Ming dynasty pointed out in the Compendium of Materia Medica, "Only when medicine is used by a gentleman and gives full play to its ability to save the world can it meet the requirements of morality." Medicine is benevolence, highlighting the ethical value of medicine, and emphasizing that the social responsibility of doctors is to save lives in the first place. Let students realize that medical students must have a humanitarian spirit of reverence and respect for life and a sense of social responsibility for helping the world and saving people.

Under the guidance of "benevolence", the course of learning medicine, medical records and achievements of famous doctors of all ages are inserted into traditional Chinese medicine courses, so as to guide students to learn the benevolence of the past doctors who see others' distress as if it's their own distress. In the outbreak of COVID-19 epidemic at the end of 2019, a large number of advanced figures and examples emerged can be combined with the classroom teaching of traditional Chinese medicine to inspire students to have the heart of benevolence and medicine and courageously shoulder the important task of the future health of the Chinese nation.

\section{Carry out all-round ideological and political classes}

The effective implementation of course ideological and political education is based on practicality and activity. It will be better only if it is designed to mobilize students' initiative, participation, emotion and experience, especially focusing on emotional experience and behavioral exercises Promote moral education ${ }^{[4]}$. This puts forward higher requirements for teachers' political quality, professional level and teaching methods. 


\subsection{Build a three-dimensional classroom}

Organically integrate inside and outside the classroom, inside and outside the school. Classroom teaching time is limited, and the unlimited effects of ideological and political education can be explored by using the time outside the classroom. Cultivate students' interest in the classroom, arouse emotional resonance, and effectively motivate them to generate learning motivation. Students can be encouraged to use the library and the Internet to learn independently by assigning open-ended questions or essay topics. Students' autonomous learning can promote their understanding, mastery, expansion and deepening of classroom knowledge. Use diversified teaching methods, such as the part of traditional Chinese medicine prescriptions, and students can be recommended to watch the documentary Herbal China; the part of internal medicine of traditional Chinese medicine can adopt situational teaching, with students as the main body, incorporating clinical cases, and inspiring students' enthusiasm and enthusiasm.

\subsection{Evaluate students' learning effects in a diversified way}

In the past, the evaluation of learning effects completely relied on the test scores of professional courses, and the test scores were not suitable for the evaluation of the ideological and political teaching effects of the courses. Therefore, the evaluation of students should be diversified. Add small essays on the theme of Chinese medicine cultural thinking, curriculum ideological and political experience, etc.; carry out group discussion and inter-group mutual evaluation, discuss a topic in a group after each chapter, adopt inter-group self-evaluation and mutual evaluation to quantify the learning effect. In addition, questionnaire surveys are carried out from time to time to allow students to make anonymous evaluations of teachers' lectures to achieve the purpose of teaching and learning.

\subsection{Improve teachers' political accomplishment}

Teachers are a key factor in educating people and achieving the goal of talent training in universities, and also a key force in the implementation and promotion of "course ideological and political education". Teachers must first have ideological awareness and strong moral quality before they can teach by precepts and deeds, and encourage students to "believe in their own way". The courses of traditional Chinese medicine in our hospital are part-timed by clinicians of Chinese medicine department. This is beneficial for teachers to pass on clinical practical experience to students, and to teach students the tastes of life that individuals experience in daily diagnosis and treatment. In daily work and life, teachers should first achieve "benevolence", take the patient as the center, not be polluted by financial interests, and infect, educate, drive and influence students through their own personality charm, and help them establish a firm ideals and beliefs to form correct values. Teachers should encourage students to be vigorous, energetic, optimistic and open-minded by maintaining their own positive and enterprising mental state, and an optimistic and healthy mentality, and help them grow into guards of the health of the Chinese nation.

\section{Summary}

The goal of medical education is to cultivate health professionals with noble morals and exquisite medical skills. In the teaching of traditional Chinese medicine, we try to integrate the ideological and political elements such as family and national feelings, socialist core values and humanistic feelings into the teaching goal of the course and the teaching practice of each class, so as to form the combination of professional knowledge teaching and ideological and moral guidance, and make use of professional advantages to carry out moral education for students.

Under the guidance of curriculum ideology and politics, we actively carry out teaching reform, constantly improve the teaching content and mode, improve the professionalism and ideological nature of traditional Chinese medicine courses in western medical colleges and universities, and train all-round medical talents with both ability and political integrity for the development of medicine in the new era.

\section{References}

[1] Xi Jinping stressed at the National Conference on Ideological and Political Work in Colleges and Universities that ideological and political work should be carried through the whole process of education and teaching to create a new situation in the development of China's higher education. People's Daily. 2016-12-09 (01).

[2] Liang Xian. Some thoughts on course ideological and political education. Education Teaching Forum. 2018; (30): 42-43.

[3] Gao Yan. The key issues and solutions of the construction of course ideological and political education. China Higher Education. 2017; (Z3): 11-14. 
[4] Ma Shuran, Zhang Baochun, Wang Tong, et al. Theoretical discussion on the integration of basic theory of Chinese medicine into curriculum ideological and political education. Modern Distance Education of Chinese Medicine. 2019; 17(08): 17-20. 